\title{
ATTENUATION OF MULTIPLE REFLECTIONS ASSOCIATED WITH DIABASE SILLS FROM SOLIMÕES BASIN, BRAZIL, THROUGH THE PARABOLIC RADON TRANSFORM AND MULTICHANNEL PREDICTIVE DECONVOLUTION
}

\author{
Misael Possidonio de Souza ${ }^{1}$, Michelangelo Gomes da Silva ${ }^{1}$ and Milton J. Porsani ${ }^{1,2}$
}

\begin{abstract}
The Solimões Basin, Brazil, will be the subject of many discussions in the future due to the success of oil exploration in the 1970s with the discovery of oil and gas fields. The geology of this basin is characterized by significant thick igneous rocks layers, the diabase sills, which can be seen in any stacked section as reflectors with strong amplitude but low frequency. The high contrast of seismic impedance between the sedimentary rock layers and the diabase sills generate multiple reflection and reverberations that can lead to wrong seismic interpretation of stacked sections. In this work, to improve the quality of the stacked sections, we propose a seismic process flow that includes multiple filtering steps in land data, throughout the Multichannel Predictive Deconvolution and the Parabolic Radon Transform. This study was first performed on synthetic data to test the methodology, and then in real data provided by Agência Nacional do Petróleo, Gás Natural e Biocombustíveis (ANP). The conventional processing flowchart was applied using commercial processing software such as SeisSpace/ProMAX, and Fortran 90 codes available in the Centro de Pesquisa em Geofísica e Geologia, Universidade Federal da Bahia (CPGG/UFBA). The results obtained were satisfactory with the methodology used, besides visible improvements in the quality of the stacked seismic sections after attenuation of unwanted noises.
\end{abstract}

Keywords: multiple attenuation, seismic processing, seismic reflection.

RESUMO. A Bacia do Solimões será ainda tema de muitas discussões no futuro, devido ao sucesso da exploração de petróleo nas décadas de 1970 com a descoberta de campos de óleo e gás. A geologia desta bacia é caracterizada por espessas camadas de rochas ígneas, as soleiras de diabásio, que podem ser vistas em toda seção empilhada como refletores com forte amplitude e baixa frequência. 0 alto contraste de impedância sísmica entre as rochas sedimentares e as soleiras de diabásio gera reflexões múltiplas e reverberações que podem levar a uma interpretação sísmica errada das seções empilhadas. Neste trabalho, para melhorar a qualidade das seções empilhadas, propomos um fluxograma de processamento que adicione etapas de filtragem de múltiplas, através da Deconvolução Preditiva Multicanal e da Transformada Radon Parabólica. Este estudo foi realizado primeiramente em dados sintéticos para testar a metodologia, e depois em dados reais cedidos pela Agência Nacional do Petróleo, Gás Natural e Biocombustíveis (ANP). 0 fluxograma de processamento convencional foi aplicado utilizando software comercial de processamento, como 0 SeisSpace/ProMAX, códigos implementados em Fortran 90 disponíveis no Centro de Pesquisa em Geofísica e Geologia, Universidade Federal da Bahia (CPGG/UFBA). Os resultados obtidos foram satisfatórios com a metodologia utilizada, além de visíveis melhorias na qualidade das seções sísmicas empilhadas após atenuação dos ruídos indesejados.

Palavras-chave: atenuação de múltiplas, processamento sísmico, sísmica de reflexão.

\footnotetext{
${ }^{1}$ Universidade Federal da Bahia, Centro de Pesquisa em Geofísica e Geologia, Instituto de Geociências, Campus Universitário da Federação, Salvador, BA, Brazil E-mails: misael.geoł@gmail.com; mykael_ba@yahoo.com.br; porsani@ufba.br

${ }^{2}$ National Institute of Science and Technology of Petroleum Geophysics (INCT/CNPq/MCTI).
} 


\section{INTRODUCTION}

The Amazon region has always attracted interest from major oil companies, despite the current scenario of oil and gas exploration in onshore basins. In the 1978s, there was an intense exploration in the Amazon region including the Solimões Basin (Eiras, 1998), where gas wells were drilled in Urucu province. This basin presents high velocities contrasts between its sedimentation and diabase sills that generate multiple reflections observed in seismic data, making processing and interpretation more difficult. This can also be observed in synthetic data modeled by finite differences method (Silva Neto, 2004).

It is also known that land seismic data have low signal-to-noise ratio (Yilmaz, 2001), due to several factors, such as environmental noise, reverberations, aerial and refracted waves, ground roll (Silva, 2004), and therefore multiple identification and filtering is not an easy task (Alái \& Verschuur, 2006). Most of these noises can be removed during conventional processing, throughout the NMO correction and stacking and $f-k$ filtering for linear or coherent noises. For multiple attenuation, there are several techniques already known in the industry for filtering, but for marine data. Some good techniques are Mono and Multichannel Predictive Deconvolution (Lima, 1999), Parabolic Radon Transform (Berkhout, 2006) and SRME method, the most robust so far (Verschuur et al., 1992).

Deconvolution aims the convolution of the seismic trace with its inverse filter in order to obtain the impulsive response of the Earth (Oliveira et al., 2014). For multiple filtering, a prediction distance is added inside the filter, which convolves only with the noise samples, preserving the signal, which is called by Predictive Deconvolution. It performs a statistical estimation of the inverse filter, throughout the Wiener-Levinson recursion, with a single trace. However, we can reinforce the inverse filter estimation using the ambiguity of seismic information, by adding more traces, which is then called Multichannel Predictive Deconvolution, a much more robust method than the previous one (Lima \& Porsani, 2001). These techniques can be applied in Common Depth Points (CDP) and OFFSET domains, being more efficient in OFFSET domain (Oliveira et al., 2014).

On the other hand, the Radon Filtering is a method based on the difference of velocities between primary and multiple reflections, and it has been widely used in large companies such as Petrobras (Fernandes, 2014). It changes the domain from CDP in time $t-x$ to the Radon domain, where we can separate primary and multiple reflections, eliminating the noise and returning to the original domain throughout the Radon
Inverse Transform (Hampson, 1986). For multiple reflections attenuation, the Parabolic Radon Transform has proven itself to be more suitable and effective for seismic data filtering (Abbad et al., 2011). This technique acts similarly to $f-k$ filtering, but it is more efficient for short offsets failing in areas where geology is very complex.

To date, there are interesting works about attenuation of multiple reflections associated with diabase in synthetic data only, with some filtering techniques that are commonly used in seismic marine data. We hereby show interesting and new results of seismic processing and multiple filtering obtained in real land data from Solimões Basin provided by the ANP (Agência Nacional do Petróleo, Gás Natural e Biocombustíveis). We present a methodology to identify multiple reflections associated with diabase sills, assuming that there is periodicity, and applying Predictive Deconvolution and Parabolic Radon.

\section{METHODOLOGY}

\section{Multichannel Predictive Deconvolution}

Predictive Deconvolution is a statistical method of multiple filtering that is based on the periodicity of the primary and multiple energy. It aims to estimate an inverse filter that operates after a predictive distance, wisely chosen, to convolve with the noise leading us to a trace with primary reflections only. It is believed to be effective for long-period multiples in the marine case. Multichannel deconvolution mathematical formulation is similar to the single channel deconvolution, both use the Wiener-Levinson (WL) recursion to estimate the inverse filter.

In the following procedure, we describe how to obtain multichannel WL filters using 3 channels and number of filter coefficients per channel equal to 3 . Let $w$, the desired data, $x$, $y$ and $z$, the three strokes, then the calculated data $w$, can be represented by the

$$
w(t)=h(t) * x(t)+f(t) * y(t)+g(t) * z(t)
$$

where $h(t), f(t)$ and $g(t)$ are operators acting respectively on the traits $x, y$ and $z$. For operators with three coefficients in each signal, the above expression can be rewritten to,

$$
w_{t}=\sum_{k=1}^{3} x_{t-k+1} h_{k}+\sum_{k=1}^{3} y_{t-k+1} f_{k}+\sum_{k=1}^{3} z_{t-k+1} g_{k}
$$


using matrix notation, we have:

$$
\mathbf{W}=\left[\begin{array}{ccccccccc}
x_{0} & 0 & 0 & y_{0} & 0 & 0 & z_{0} & 0 & 0 \\
x_{1} & x_{0} & 0 & y_{1} & y_{0} & 0 & z_{1} & z_{0} & 0 \\
\vdots & x_{1} & x_{0} & \vdots & y_{1} & y_{0} & \vdots & z_{1} & z_{0} \\
x_{M} & \vdots & x_{1} & y_{M} & \vdots & y_{1} & z_{M} & \vdots & z_{1} \\
0 & x_{M} & \vdots & 0 & y_{M} & \vdots & 0 & z_{M} & \vdots \\
0 & 0 & x_{M} & 0 & 0 & y_{M} & 0 & 0 & z_{M}
\end{array}\right]
$$

where $\mathbf{W}$ is a block Toeplitz matrix from the traces $x_{t}, y_{t}$ and $z_{t}$ with $M$ samples. We can then define $\mathbf{a}^{\mathbf{T}}$ by:

$$
\mathbf{a}^{\mathbf{T}}=\left[\begin{array}{lll}
\mathbf{h}^{\mathbf{T}} & \mathbf{f}^{\mathbf{T}} & \mathbf{g}^{\mathbf{T}}
\end{array}\right]
$$

where the vectors $\mathbf{h}, \mathbf{f}$ and $\mathbf{g}$ are formed by the operators $h_{t}, f_{t}$ and $g_{t}$. For a random vector $\mathbf{a}$, we can relate the predicted error vector by:

$$
\mathbf{e}=\mathbf{W}-\mathbf{W a}
$$

minimizing the quadratic error, we find:

$$
Q(\mathbf{a})=\mathbf{e}^{\mathbf{T}} \mathbf{e}
$$

and obtaining the Normal Equations, whose solution provides WL multichannel predictive filter. It is possible to estimate a filter with more than 3 channels, as long as your seismic data supports. Therefore, it is expected that the output of multichannel deconvolution shows an improvement in multiple filtering when compared with single channel deconvolution.

\section{The Parabolic Radon Transform}

The Parabolic Radon Transform maps parabolic events with different apertures where the amplitudes are summed along these parabolas, resulting in points or regions of coherence in the $\tau-q$ domain, with the different parabolas being concentrated in different regions. Hampson was the first to introduce its applications in seismic data. Basically, the data are organized into $\mathrm{CDP}$ families, and the NMO correction is done. An approximation of the travel time in the parabolic form is expressed in the equation below as:

$$
t=\tau+q x^{2}
$$

where $\tau$ represents the intercept time or zero-offset time and $q$, the curvature of this parabola. Thus, the seismic data, $D\left(x_{n}, t\right)$ in the $x-t$ (CDP-OFFSET) domain, can be represented by the Direct Radon Transform $M\left(q_{j}, \tau\right)$ in the $\tau-q$ domain, given by:

$$
D\left(x_{n}, t\right)=\sum_{j=1}^{N_{q}} M\left(q_{j}, \tau=t-q_{j} x_{n}^{2}\right),
$$

where $N_{q}$ is the number of $q$ parameters. However, the Inverse Radon Transform is not fully reversible, which is a problem related to the discretization of the data and various limitations associated with the acquisition. We calculate the Fourier Transform of $D\left(x_{n}, t\right)$, that is $d\left(x_{n}, f\right)$, leading us to:

$$
d\left(x_{n}, f\right)=\sum_{j=1}^{N_{q}} m\left(q_{j}, f\right) e^{i 2 \pi f q_{j} x_{n}^{2}},
$$

and using a matrix notation we have:

$$
\mathbf{d}(\mathbf{f})=\mathbf{L}(\mathbf{f}) \mathbf{m}(\mathbf{f})
$$

where the operator $\mathbf{L}$ is given by:

$$
\mathbf{L}=\left[\begin{array}{ccccc}
e^{-i 2 \pi f q_{1} x_{1}^{2}} & e^{-i 2 \pi f q_{2} x_{1}^{2}} & e^{-i 2 \pi f q_{3} x_{1}^{2}} & \ldots & e^{-i 2 \pi f q_{j} x_{1}^{2}} \\
e^{-i 2 \pi f q_{1} x_{2}^{2}} & e^{-i 2 \pi f q_{q_{2}} x_{2}^{2}} & e^{-i 2 \pi f q_{3_{3}} x_{2}^{2}} & \ldots & e^{-i 2 \pi f q_{j} x_{2}^{2}} \\
\vdots & \vdots & \vdots & \vdots & \vdots \\
e^{-i 2 \pi f q_{1} x_{k}^{2}} & e^{-i 2 \pi f q_{2} x_{k}^{2}} & e^{-i 2 \pi q_{3_{3}} x_{k}^{2}} & \ldots & e^{-i 2 \pi q_{j} x_{k}^{2}}
\end{array}\right]
$$

Therefore, the Direct Radon Transform (DRT) can be calculate by:

$$
\mathbf{m}=\mathbf{L}^{H} \mathbf{d}
$$

and the Inverse Radon Transform (IRT) can be estimated by least squares method, leading us to the expression:

$$
\mathbf{d}=\left(\mathbf{L} \mathbf{L}^{H}\right)^{-1} \mathbf{L m}
$$

where $\mathbf{L}$ and $\mathbf{L}^{H}$ are an adjoint par of operators.

\section{The Parameter $q$}

In industry, Radon domain is not defined by the curvature of the parabola. We see the Radon domain as time of intersection $\tau$ versus against move-out $(q)$ in time, instead. Most authors prefer to use Radon Filtering this way because it is more suitable. The parameter $q$ of a parabola (a CDP after NMO correction) with intercept time $\tau$ are related by the following equation (Fernandes, 2014):

$$
\tau=t-q \frac{x^{2}}{x_{M A X}^{2}}
$$

where $x$ represents the OFFSET and $x_{M A X}$, the maximum OFFSET. From this equation, the parameter $q$ becomes the move-out time (ms). We can see that in many seismic processing software, such as SeisSpace/ProMAX, the Radon domain comes with $\tau-p$, with $p$ being the move-out of a parabola. 


\section{The Seismic Processing Workflow}

The process is divided into the following steps:

(i) Quality Control, Geometry and Mute/Edition;

(ii) First break picking and Field Statics Corrections;

(iii) Spike deconvolution and Ground Roll Filtering;

(iv) First Velocity Analysis and Stack;

(v) Multiple Reflection Identification and Filtering;

(vi) Second Velocity Analysis, Residual Stack Correction and Seismic Migration.

In this work, processing started importing the SEG-Y field files into the SeisSpace/ProMAX for geometry assembly. The next step consists of editing and muting noisy traces and defective stations in land data. Next, first breaks picking is performed to be used in statics corrections, in order to eliminate the effects of the weathering layer and irregular topography. The next step is the ground roll filtering, using the available tools in SeisSpace/ProMAX.

To apply deconvolution, data were, at first, exported to Seismic Unix, where they were organized in the CDP gathers. We applied MMO (Multiple Moveout Correction), which is an NMO correction using the velocity of primary reflection. We applied Multichannel Predictive Deconvolution and its results were re-imported into SeisSpace/ProMAX in SEG-Y format, where amplitude gains and spherical divergence correction and NMO correction were applied before stacking.

On the other hand, to use Radon Parabolic Transform, we applied NMO correction in the data organized in CDP domain in order to separate the primary and multiple reflections by their different move-outs. Data were then passed to Radon domain where the primary reflections showed a negative move-out $-q$ and the multiples reflections and reverberations showed a positive move-out $+q$.

After selecting the primary reflection region by applying a simple mute, we turned back to time domain through Radon Parabolic Inverse Transform, generating a filtered CDP as an output. At the end, we applied MMO correction in these filtered CDP gathers by both methods in order to compare and visualize their effect on multiples.

\section{Multiple Reflection Identification on Land Data}

The reflections of the diabase sill are easily recognized in any seismic line from the Solimões Basin, which presents high amplitude due to the strong contrast of seismic impedance. After identifying the diabase layer, in the stacked section, we also identified the multiple reflections in a similar way it is done in marine seismic data. For this, we organized the data in CDP and applied constant NMO correction only in the reflection corresponding to the diabase layer. After MMO correction, it is expected that all seismic events of same velocity will be flatted, and consequently, the multiple associated with the diabase will stand out in front of the other events.

This methodology is also similar to the Predictive Deconvolution for multiple reflection attenuation and it is proven to be reliable. For example, if we would choose any other strong reflection without any multiple reflections associated with it, we would not find anything. On the other hand, choosing the diabase sill reflector, and applying NMO correction in a CDP in order to make it flat (MMO correction), all the multiple reflections associated with the sill will be visible, and also become flat.

In future work, it is proposed to use the SRME method to automatically predict all multiple reflections on Solimões Basin data, instead of the methodology presented here, due to the amount of time the interpreter would take to identify the noises. SRME performs the auto-convolution with the seismic data with itself showing us where the multiple reflections are located and being faster than other methods to identify multiple reflections.

\section{NUMERICAL RESULTS ON SYNTHETIC AND REAL DATA FROM SOLIMÕES BASIN}

Aiming to test our methodology, synthetic data were generated by Finite Difference method based on a velocity field (Fig. 1), which was created following the main geological features of Solimões Basin. The geometry of seismic modeled data is also illustrated in Table 1.

Table 1 - Acquisition parameters of the synthetic data.

\begin{tabular}{|l|c|}
\hline Number of shots and channels & 100 \\
\hline Fold & 50 \\
\hline Geometry & $1000 \mathrm{~m}-20 \mathrm{~m}-\mathrm{x}-20 \mathrm{~m}-1000 \mathrm{~m}$ \\
\hline Shot and receiver interval & $20 \mathrm{~m}$ \\
\hline Total time of record & $5 \mathrm{~s}$ \\
\hline Sampling interval & $2 \mathrm{~ms}$ \\
\hline
\end{tabular}

We applied MMO correction with the velocity of $2000 \mathrm{~m} / \mathrm{s}$ in the data, sorted by CDP and absolute offsets, and all multiple 


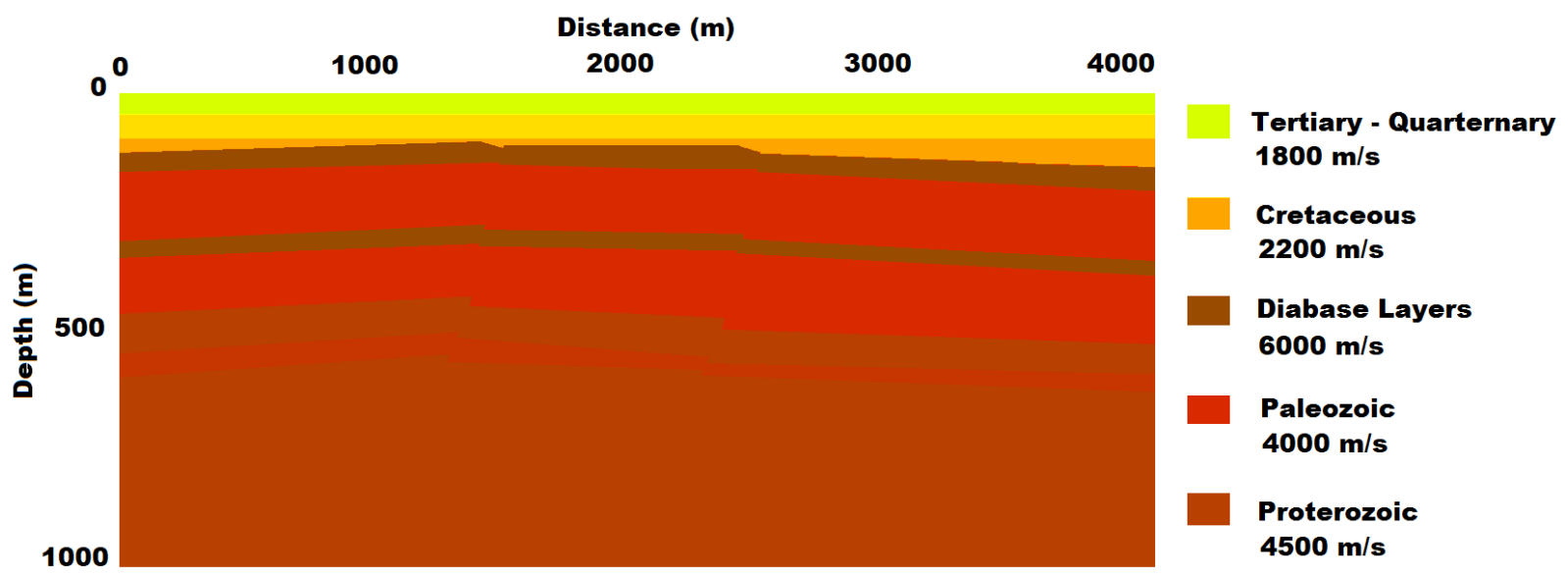

Figure 1 - Velocity field from Solimões Basin for seismic modeling.

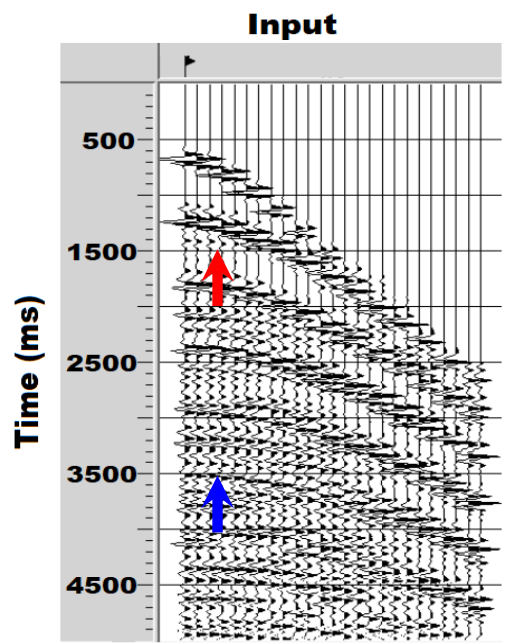

(a)

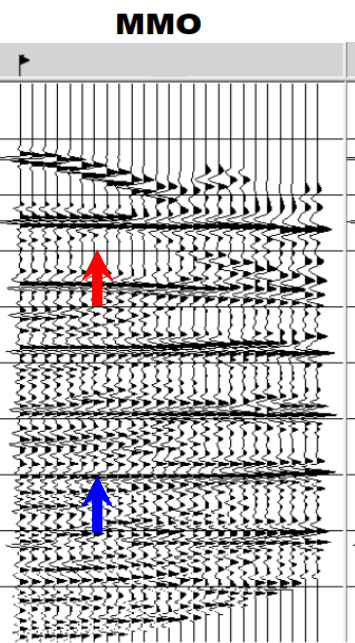

(b)
MMO + DEC $+$

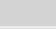

Filtered output

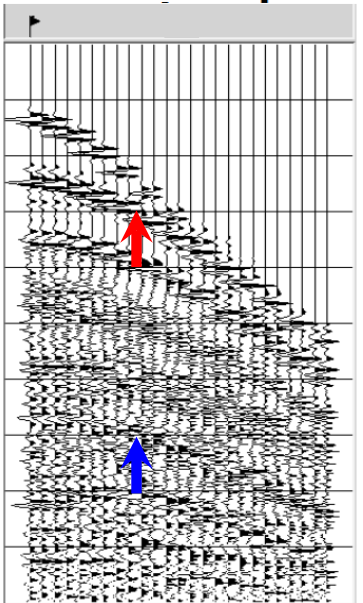

(d)

Figure 2 - Multichannel Predictive Deconvolution applied in a single modeled CDP. Main steps are shown from input (a), MMO correction (b), filtering (c) and inverse MMO correction (d). The red arrows indicate the primary reflection, the diabase sill, and the blue arrows indicate some of the multiple reflections.

reflections associated with this reflection became flat. So, we selected a single CDP (Fig. 2a) and the input of deconvolution has to be MMO corrected (Fig. 2b). The period between primary reflections and multiple has also to be known. Multichannel Predictive Deconvolution was then applied using 7 channels (Fig. 2c) and the results were very effective on modeled data after MMO inverse correction (Fig. 2d).

The results of a stacked section obtained from synthetic data before and after deconvolution are shown in Figure 3 . It is hard to see underneath the diabase layer due to these noises and reverberations before filtering (Fig. 3a) and the output section is closer to the original velocity field, which is more reliable (Fig. 3b).

The results of Parabolic Radon Filtering in synthetic data are shown with the same CDP chosen in previous figures (Fig. 4). The most important parameter is, in fact, the move-out difference between the signal and noise, which is determined by the velocity contrast. We applied an NMO correction with intermediate velocity before the Parabolic Radon Transform (Fig. 4a), leading us to a scenario where primaries reflections have negative move-out and multiples have positive move-out (Fig. 4b). 


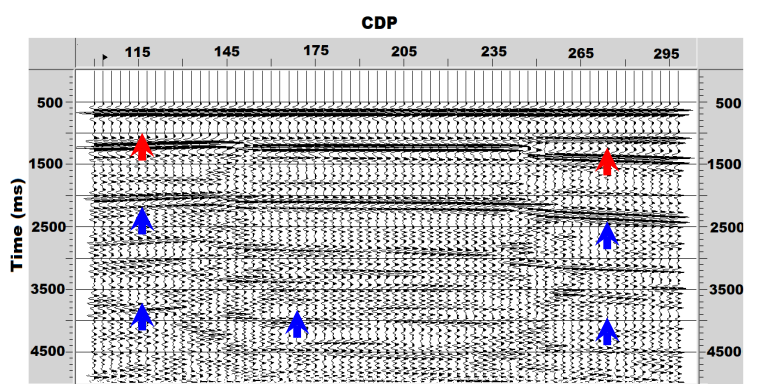

(a) Original Stack

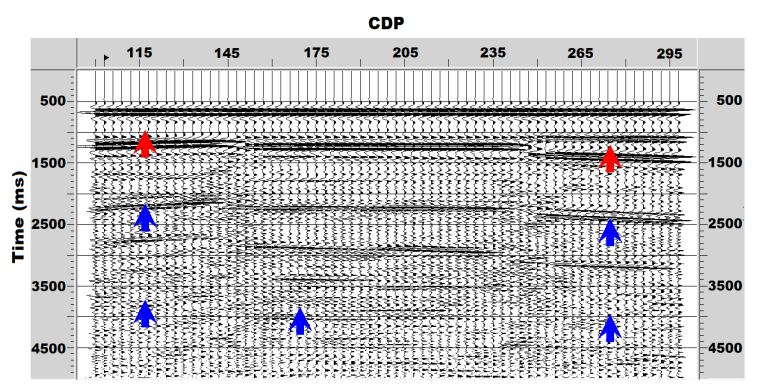

(b) Filtered Stack

Figure 3 - Display of SeisSpace/ProMAX illustrating stacked sections from synthetic data, before deconvolution in (a), after deconvolution in (b).

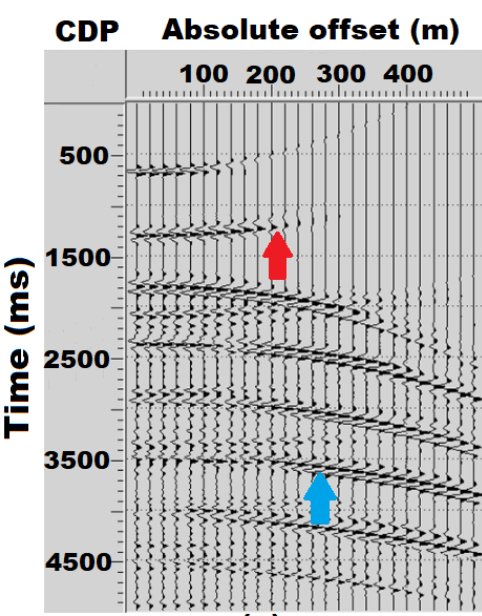

(a)

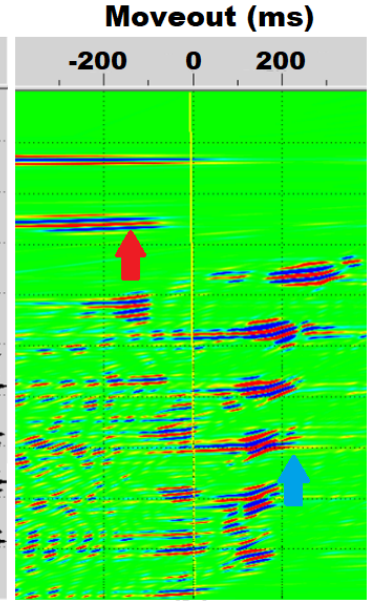

(b)

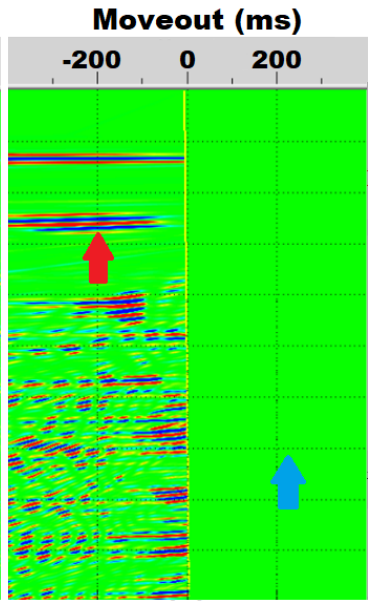

(c)
Absolute offset (m)

100200300400

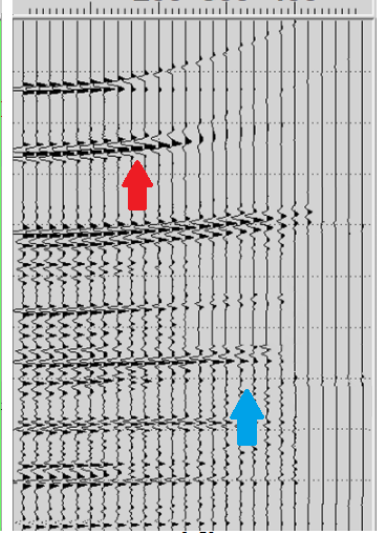

(d)

Figure 4 - Display of SeisSpace/ProMAX showing a CDP after NMO correction with RMS intermediate velocity (a), Parabolic Radon domain (b), mute in the multiple region (c) and the output after Inverse Transform (d). The red arrows indicate the primary reflection, the diabase sill, and the blue arrows indicate some of the multiple reflections.

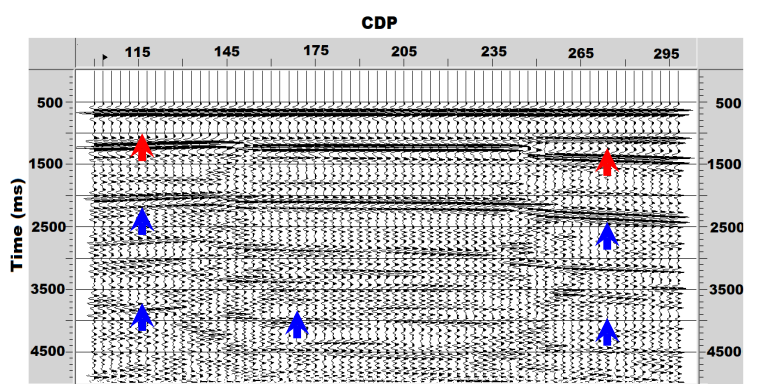

(a) Original Stack

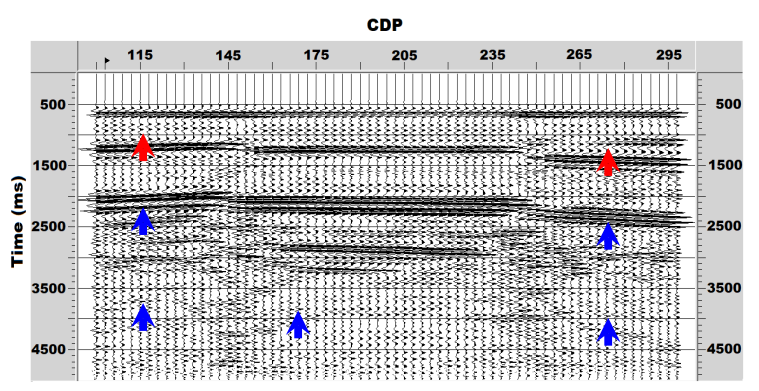

(b) Filtered Stack

Figure 5 - Display of SeisSpace/ProMAX illustrating stacked sections from synthetic data, before Parabolic Radon Filtering (a) and after it (b). 
We could mute the noisy area in the Radon domain (Fig. 4c) and then came back to time domain by applying Inverse Parabolic Radon Transform (Fig. 4d). We can see how effective this technique is by the quality of the filtered output. An inverse NMO correction with intermediate velocity is required before following the processing flow.

We show the results of a stacked section obtained from the synthetic data before (Fig. 5a) and after Radon Filtering (Fig. 5b). The quality is better when compared to the stacked section filtered by Deconvolution (Fig. 3b), which is closer to the original velocity field. In addition, Radon Filtering does not require any previous knowledge about how the multiple reflections were generated and does not assume periodicity in seismic data, becoming easier to perform than Deconvolution.

The real land seismic line from Solimões Basin was given by ANP as a research support. We followed the seismic

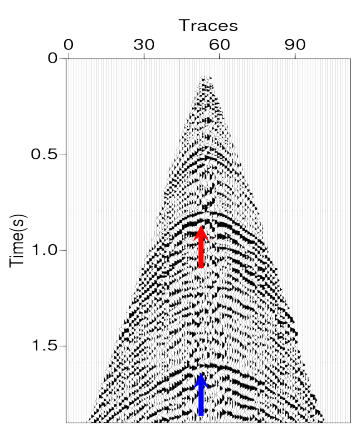

(a)

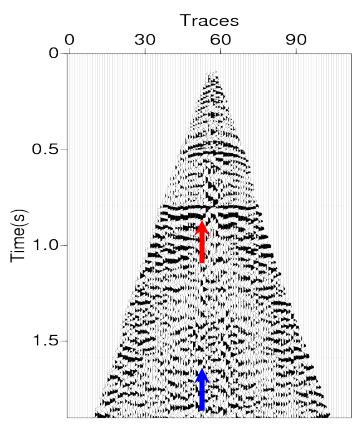

(c)

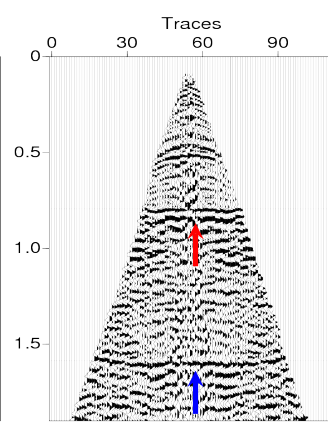

(b)

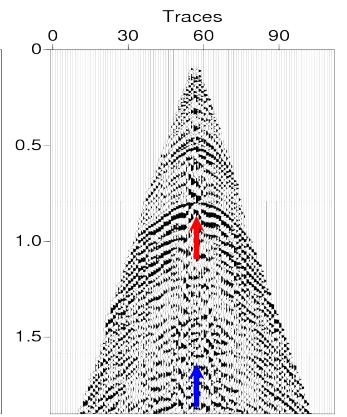

(d) processing steps previous explained. The geometry of this seismic data is shown in Table 2.

Table 2 - Acquisition parameters of the seismic line 0254-0264 of the Solimões Basin.

\begin{tabular}{|l|c|}
\hline Number of Shots & 1225 \\
\hline Number of channels & 240 \\
\hline Fold & 120 \\
\hline Shot and receiver interval & $25 \mathrm{~m}$ \\
\hline Minimum OFFSET & 50 \\
\hline Maximum OFFSET & 3025 \\
\hline Total time of record & $4 \mathrm{~s}$ \\
\hline Sampling interval & $2 \mathrm{~ms}$ \\
\hline
\end{tabular}

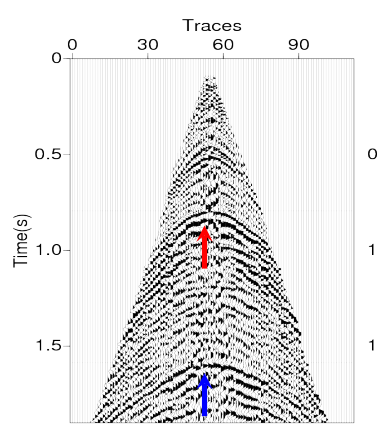

(a)

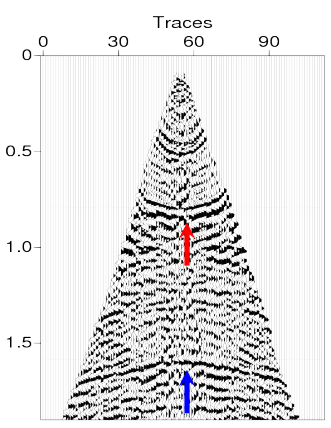

(b)

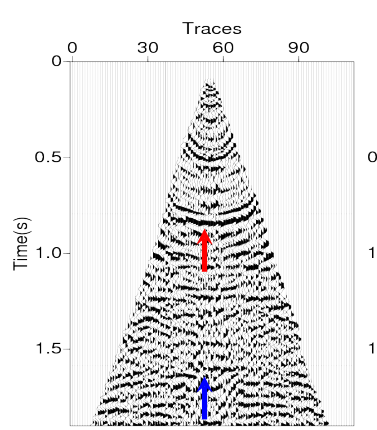

(c)

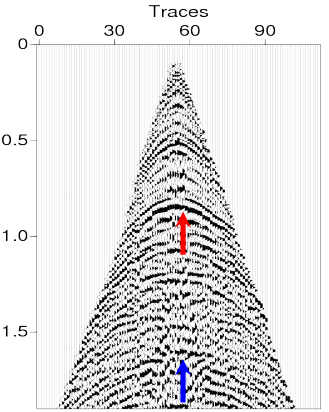

(d)
Figure 6 - Deconvolution steps for multiple attenuation in real data: a CDP gather in (a), after MMO correction on diabase layer in $0.8 \mathrm{~s}(\mathrm{~b})$, after multichannel deconvolution with 5 traces (c) and after MMO inverse correction (d). The red arrows indicate the primary reflection, the diabase sill, and the blue arrows indicate the multiple reflections.
Figure 7 - Parabolic Radon Filtering steps for multiple attenuation in real data: a CDP gather (a), after NMO correction with intermediate velocity (b), after Radon Filtering (c) and after NMO inverse correction (d). The red arrows indicate the primary reflection, the diabase sill, and the blue arrows indicate the multiple reflections. 


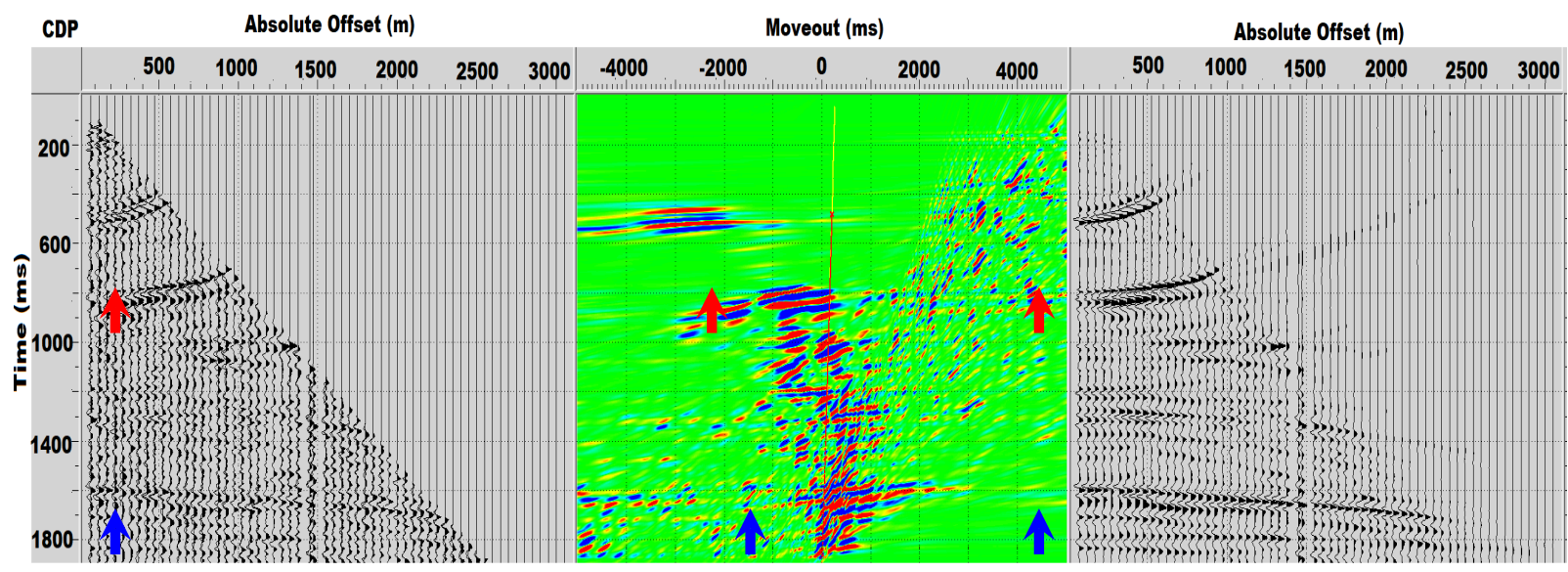

(a) CDP gather and its Radon domain before muting

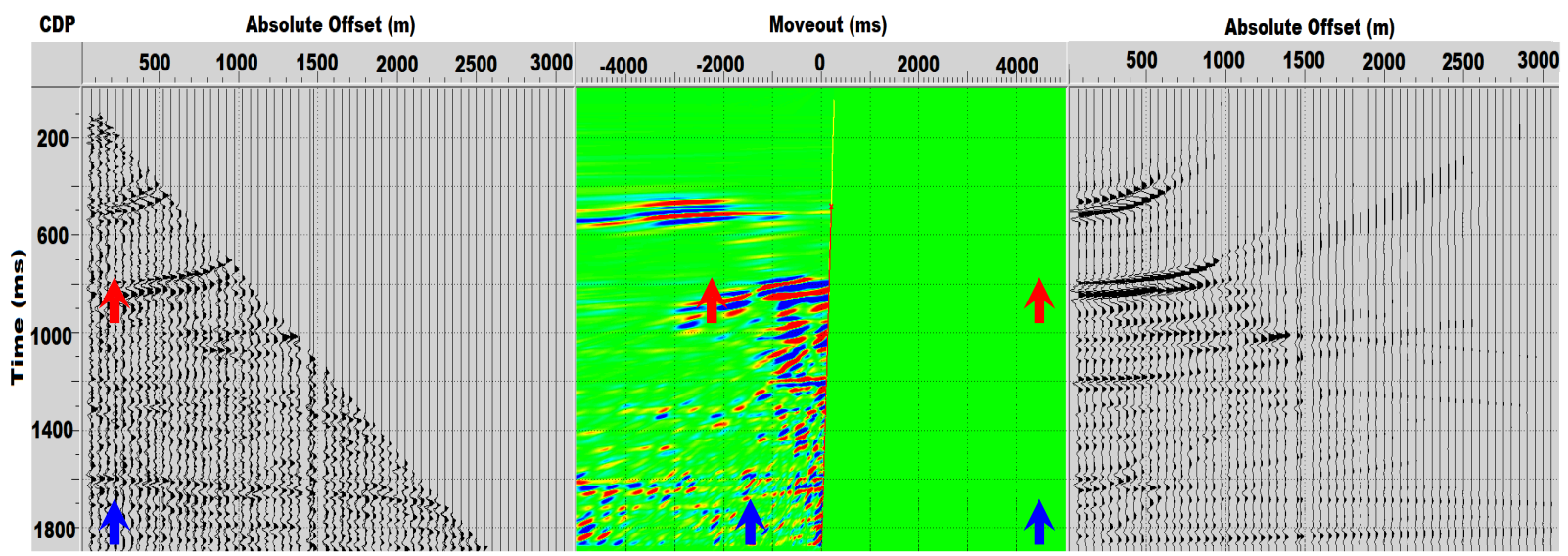

(b) CDP gather and its Radon domain after muting

Figure 8 - Display of SeisSpace/ProMAX showing a real CDP gather after NMO correction with RMS intermediate velocity, its Parabolic Radon domain and its Inverse Transform (a); The same CDP here after a mute applied in the multiple reflections region and its Inverse Transform (b). The red arrows indicate the primary reflection, the diabase sill, and the blue arrows indicate the multiple reflections.

After applying the processing flow to improve the signal-to-noise ratio, a CDP gather was chosen to run Multichannel Predictive Deconvolution and Parabolic Radon tests. In this CDP gather (Fig. 6a) we see the diabase layer in $0.8 \mathrm{~s}$ and its multiple associated in 1.6s, approximately. In order to perform Deconvolution, MMO correction was applied using a velocity of $2200 \mathrm{~m} / \mathrm{s}$ on $0.8 \mathrm{~s}$ (Fig. 6b). After that, the multiple reflection also showed a zero move-out. The Multichannel Predictive Deconvolution was applied (Fig. 6c) followed by an MMO inverse correction to generate the output filtered data (Fig. 6d).
A similar procedure was made for Radon Filtering. Firstly, the same CDP gather (Fig. 7a) was NMO corrected with an intermediate RMS velocity (Fig. 7b) in order to create a different move-out between primaries and multiples. After that, Radon Transform was applied, followed by a mute the noisy region, generating a filtered CDP without multiples (Fig. 6c). An NMO inverse correction was also required (Fig. $6 \mathrm{~d}$ ) to generate the output data. In the Radon domain, we can see the primaries and multiples of diabase layer are separated by its move-out (Fig. 8a). A mute function was designed and applied in order to eliminate those noises from seismic data before coming back 


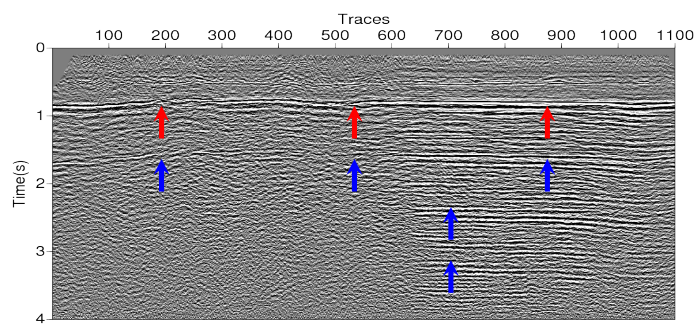

(a) Original Stack with MMO correction

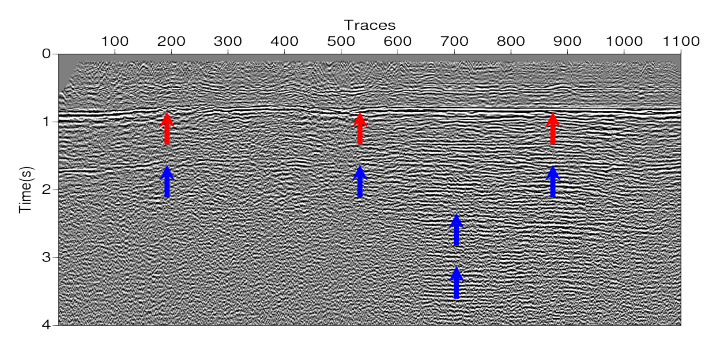

(b) After deconvolution

Figure 9 - Stacked sections from real data with MMO correction (a) and after deconvolution (b). The red arrows indicate the primary reflection, the diabase sill, and the blue arrows indicate the multiple reflections.

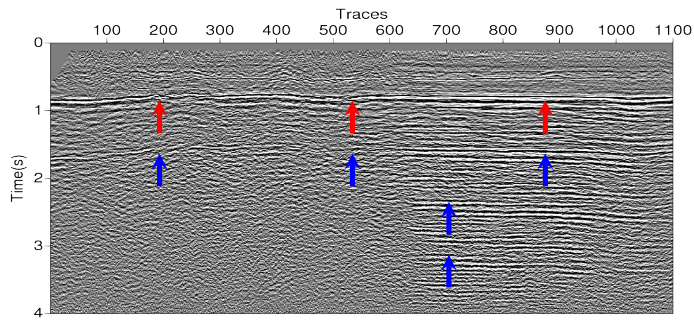

(a) Original Stack with MMO correction

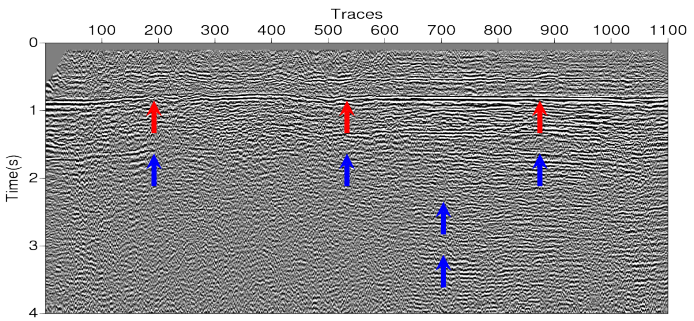

(b) Stack After Radon

Figure 10 - Stacked sections from real data with MMO correction (a) and after Parabolic Radon Filtering (b). The red arrows indicate the primary reflection, the diabase sill, and the blue arrows indicate the multiple reflections.

to the CDP-OFFSET domain (Fig. 8b) throughout the Inverse Transform.

Despite the low signal-to-noise ratio, good results were observed using these techniques. Thus, for evaluation of the method, MMO correction was applied to all filtered CDPs and then stacked sections were generated, where only primary and multiple reflections would be present (Fig. 9) and (Fig. 10). The MMO stacked sections before deconvolution (Fig. 9a) shows many noises and reverberations that were eliminated (Fig. 9b) by multichannel deconvolution. On the other hand, MMO stacked section after Radon Filtering shows more improvement in quality (Fig. 10b) than the (Fig. 9b), which is more reliable for the geophysical interpretation of the whole data.

\section{CONCLUSIONS}

Solimões Basin, an intracratonic Paleozoic type, is located in Amazon State, north of Brazil. The seismogram is contaminated by multiple reflections associated to diabase sills, which has great amplitudes and low frequency. Multiple energy generated by diabase sills can also be attenuated to improve seismic image quality.

Filtering techniques commonly applied in marine seismic data can be adapted for land data as we could see the results of Radon and Deconvolution, both were quite effective methods for attenuation of multiple associated to igneous rocks. Real and synthetic data were filtered effectively by the proposed methodology.

The problems with elevation and thickness of the weathering layer with low signal-to-noise ratio common in land data can be bypassed in order to guarantee the effectiveness of the Multichannel Predictive Deconvolution method. Radon Filtering showed more improvement in the seismic image than the Deconvolution. The choice of the number of channels for deconvolution interferes greatly in the obtained results: the filtering can be quite aggressive when worked with more than 7 channels.

Noise attenuation was satisfactory at the end of the stacked section, where the multiple reflections had a larger amplitude. 
However, Parabolic Radon Transform is a high-intensity computer process depending on the sample rate of the seismic data and Deconvolution can be faster, being more computationally efficient in some cases, such as 3D seismic filtering. Finally, both methods could present satisfactory results and improve the velocity analysis of seismic data from Solimões Basin.

In future works, we propose a study with SRME method adapted for land seismic data in Solimões Basin and it is expected to show all kinds of noises associated with the diabase sills. A 3D seismic data processing and filtering is also a great subject to research in this time.

\section{ACKNOWLEDGMENTS}

The authors thank ANP for the data set from Solimões Basin and Landmark for the educational licenses granted to the Centro de Pesquisa em Geofísica e Geologia (CPGG-UFBA). This study was financed in part by the Coordenação de Aperfeiçoamento de Pessoal de Nível Superior - Brazil (CAPES) - Finance Code 001.

\section{REFERENCES}

ABBAD B, URSIN B \& PORSANI MJ. 2011. A fast, modified parabolic Radon transform. Geophysics, 76(1): V11-V24.

ALÁ'I R \& VERSCHUUR E. 2006. Case study of surface-related and internal multiple elimination on land data. In: SEG/New Orleans 2006 Annual Meeting. 62: 2727- 2731.

BERKHOUT AJ. 2006. Seismic processing in the inverse data space. Geophysics, 71(4): A29-A33.

EIRAS JF. 1998. Tectônica, sedimentação e sistemas petrolíferos da Bacia do Solimões, estado do Amazonas. In: TAHA M. (Coord.). Searching for Oil and Gas in the land of giants: The Search Magazine. Special publication - Brazil. Argentina: Schlumberger.
FERNANDES FV. 2014. Atenuação de reflexões múltiplas utilizando a Transformada Radon Parabólica. Master Dissertation on Geophysics Centro de Graduação em Geofísica e Geologia, Universidade Federal da Bahia, Salvador, Brazil, 2014. 179 pp.

HAMPSON D. 1986. Inverse velocity stacking for multiple elimination. Journal of the Canadian Society of Exploration Geophysicists, 22: 44-55.

LIMA AP. 1999. Deconvolução de reflexões múltiplas nos domínios $t-x$ e $\tau-p$ com filtros multicanais. Master Dissertation on Geophysics Centro de Graduação em Geofísica e Geologia, Universidade Federal da Bahia, Salvador, Brazil, 1999.74 pp.

LIMA AP \& PORSANI MJ. 2001. Deconvolução preditiva de reflexões múltiplas e peg-legs utilizando filtragem Wiener-Levinson multicanal. Brazilian Journal of Geophysics, 19(3): 303-313.

OLIVEIRA SLR, MACIEL RC, SILVA MG \& PORSANI MJ. 2014. Attenuation of short-period multiples in seismic data processing of the Jequitinhonha Basin, Brazil. Brazilian Journal of Geophysics, 32(3): 395-403.

SILVA NETO FA. 2004. Modelagem Acústica por diferenças finitas e elementos finitos em 2-D e 2,5-D. Master Dissertation on Geophysics. Centro de Geociências, Universidade Federal do Pará, Belém, Brazil, 2004. $103 \mathrm{pp}$

SILVA MG. 2004. Processamento de dados sísmicos da Bacia do Tacutu. Master Dissertation on Geophysics - Centro de Graduação em Geofísica e Geologia, Universidade Federal da Bahia, Salvador, Brazil, 2004. 143 pp.

VERSCHUUR DJ, BERKHOUT AJ \& WAPENAAR CPA. 1992. Adaptative surface-related multiple elimination. Geophysics, 57(9): 1166-1177.

YILMAZ 0. 2001. Seismic data analysis: processing, inversion and interpretation of seismic data. Tulsa, OK: SEG. 2027 pp. 